\title{
Influence of additional compounds on coercivity of sintered Nd-Fe-B magnets
}

\author{
Thanh Pham ${ }^{1,2}$, Duong Nguyen ${ }^{2,3}$, Yen Nguyen ${ }^{1,2}$, Lam Nguyen $^{3}$, Quang Dinh ${ }^{4}$, Ngoc Nguyen ${ }^{4}$, Koledov Victor ${ }^{5}$, \\ Kamantsev Alexander ${ }^{5}$, Mashirov Alexey, and Dan Nguyen ${ }^{1,2}$ \\ ${ }^{1}$ Institute of Materials Science, Vietnam Academy of Science and Technology, 18 Hoang Quoc Viet, Hanoi, Viet Nam \\ ${ }^{2}$ Graduate University of Science and Technology, Vietnam Academy of Science and Technology, 18 Hoang Quoc Viet, Hanoi, \\ Viet Nam \\ ${ }^{3}$ Faculty of Physics, Hanoi Pedagogical University 2, 32 Nguyen Van Linh, Vinh Phuc, Viet Nam \\ ${ }^{4}$ Hong Duc University, 565 Quang Trung, Dong Ve, Thanh Hoa, Viet Nam \\ ${ }^{5}$ Kotelnikov Institute of Radio-engineering and Electronics of RAS, Moscow, Russia
}

\begin{abstract}
In this paper, we investigated the influence of additional compounds of $\mathrm{Dy}-\mathrm{Nb}-\mathrm{Al}, \mathrm{Nd}-\mathrm{Cu}-$ $\mathrm{A} 1 \ldots$ on the coercivity of the sintered $\mathrm{Nd}_{16.5} \mathrm{Fe}_{77} \mathrm{~B}_{6.5}$ magnets. The additional compounds were first prepared by arc-melting method and then ground into particles with size in the range of $40-80 \mathrm{~nm}$ using a high energy ball milling method. After that, the additional powder were mixed with micrometer $\mathrm{Nd}-\mathrm{Fe}-\mathrm{B}$ powder before magnetic anisotropic pressing, vacuum sintering and annealing. The structure of the magnets was thoroughly analyzed using X-ray diffraction and electron microscopy techniques. The magnetic properties of the magnets were investigated on a pulsed field magnetometer. The results show that the coercivity of the sintered Nd-Fe-B magnets can be improved by introducing additional nanoparticles to their grain boundaries. The improvement of the coercivity of the magnets is clearly dependent on composition and fraction of the additional compounds. The coercivity has been enhanced $40 \%$ for the magnets by adding $3 \mathrm{wt} \%$ of the Dy-free compound of $\mathrm{Nd}_{40} \mathrm{Cu}_{30} \mathrm{Al}_{30}$.
\end{abstract}

\section{Introduction}

Due to excellent magnetic properties such as the high saturation magnetization $\left(\mathrm{M}_{\mathrm{s}}=16 \mathrm{kOe}\right)$ and large magnetocrystalline anisotropy $\left(\mathrm{H}_{\mathrm{A}}=75 \mathrm{kOe}\right)$ of the $\mathrm{Nd}_{2} \mathrm{Fe}_{14} \mathrm{~B}$ phase, the sintered $\mathrm{Nd}-\mathrm{Fe}-\mathrm{B}$ magnets are widely applied in practice $[1,2]$. However, the rapid decrease of the coercivity $\mathrm{H}_{c}$ by the thermal demagnetization limits applications of the magnets in the devices with high operating temperature $\left(\sim 200^{\circ} \mathrm{C}\right)$ such as motors, generators... [3]. Because the decrease of the coercivity leads to the reduction of power and efficiency of the devices, a requirement of sintered Nd-Fe-B magnets for these applications is high coercivity. Previous investigations have shown that the coercivity of this type of Nd-Fe-B magnets can be enhanced by new technology measures such as multi-stage heat treatment, grain boundary diffusion, element addition... [4-10]. Especially, the addition of compound containing Dy, Al, $\mathrm{Cu}, \mathrm{Nb} \ldots$ to grain boundary is more and more concerned to study [11-18]. Each element in additional compounds differently affects on the magnetic properties of the magnets. With addition of compound containing Dy, the coercivity is considerably increased by the formation $(\mathrm{Nd}, \mathrm{Dy})_{2} \mathrm{Fe}_{14} \mathrm{~B}$ phase with high magnetocrystalline anisotropy. Meanwhile, the remanence $B_{r}$ of the magnets is little decreased due to the anti-ferromagnetic coupling between $\mathrm{Fe}$ and $\mathrm{Dy}$. It is known that the magnetic properties of sintered Nd-Fe-B magnets are dependent not only on the intrinsic properties of the hard magnetic phase $\mathrm{Nd}_{2} \mathrm{Fe}_{14} \mathrm{~B}$, but also on the microstructure of the material. Other research results have been confirmed that both of $\mathrm{Al}$ and $\mathrm{Cu}$ do not enter the $\mathrm{Nd}_{2} \mathrm{Fe}_{14} \mathrm{~B}$ phase, hence the intrinsic properties $\left(\mathrm{M}_{\mathrm{S}}\right.$ and $\left.\mathrm{H}_{\mathrm{A}}\right)$ of the $\mathrm{Nd}_{2} \mathrm{Fe}_{14} \mathrm{~B}$ grains remain unchanged. These elements of $\mathrm{Al}$ and $\mathrm{Cu}$ mainly help to improve microstructure such as uniform distribution of grain boundaries, controlling of the particle size... As for $\mathrm{Nb}$, it has the effect to destroy the disadvantage crystalline Fe-rich areas to improve the corrosion resistance ability and increase the coercivity of the magnets. In this work, the influence of the additional compounds of Dy-Nb-Al, $\mathrm{Nd}-\mathrm{Cu}-\mathrm{Al} \ldots$ on the coercivity of the sintered Nd-Fe-B magnets was investigated.

\section{Experimental}

The pre-alloys with nominal composition of $\mathrm{Nd}_{16.5} \mathrm{Fe}_{77} \mathrm{~B}_{6.5}$ were prepared from $\mathrm{Nd}$, Fe and $\mathrm{FeB}(18 \%$ $\mathrm{B})$ on an induction furnace for about 30 minutes under $\mathrm{Ar}$ gas to avoid oxidation. The resulted ingots was crashed into small pieces with size smaller 2 centimeters, coarsely milled and was then fine milled in $8 \mathrm{~h}$ by using ball milling method. Industrial white gasoline was used as a solvent during milling process to avoid oxygenation.

Corresponding author: thanhpt@ims.vast.ac.vn 
The additional alloys with compositions of $\mathrm{Nd}_{40} \mathrm{Cu}_{30} \mathrm{Al}_{30}$ (P1), $\quad \mathrm{Dy}_{40} \mathrm{Nb}_{30} \mathrm{Al}_{30} \quad(\mathrm{P} 2), \quad \mathrm{Dy}_{40} \mathrm{Zr}_{30} \mathrm{Al}_{30} \quad$ (P3) and $\mathrm{Nb}_{40} \mathrm{Cu}_{30} \mathrm{Al}_{30}(\mathrm{P} 4)$ were first prepared by an arc-melting furnace. These additional alloys were then pulverized by high energy ball milling method with milling time of $4 \mathrm{~h}$ to create nanoparticles with size smaller than $100 \mathrm{~nm}$. The solvent/material and ball/powder ratios are $1 / 1$ and $4 / 1$, respectively. The Nd-Fe-B powder were mixed with the powder of additional compounds with the various weight fractions. The mixed powder was compressed with a pressure of $15 \mathrm{MPa}$, into rectangular parallelepiped tablets $\left(6.5 \times 5.5 \times 3.5 \mathrm{~cm}^{3}\right)$ in an oriented magnetic field, yielded by an electromagnet, of about 20 $\mathrm{kOe}$. The pressed magnet tablets were then sintered at $1080^{\circ} \mathrm{C}$ for $1 \mathrm{~h}$ in vacuum. After that, these magnets were heat-treated to improve their coercive force. A twostage heat treatment process was chosen and carried out using a vacuum furnace. At the first stage, the magnets were heated at $\mathrm{T}_{\mathrm{a} 1}=820^{\circ} \mathrm{C}$ for $1 \mathrm{~h}$ and then fast cooled down to room temperature. For the second stage, magnets were heated at temperatures, $\mathrm{T}_{\mathrm{a} 2}$, of $540^{\circ} \mathrm{C}$ for 1 $\mathrm{h}$ and quenched rapidly by Ar gas. For both the stages, the samples were heated with the rate of $30^{\circ} \mathrm{C} / \mathrm{min}$ and quenched rapidly with the rate of about $50^{\circ} \mathrm{C} / \mathrm{min}$. The structure of the materials was thoroughly analyzed by using X-ray diffraction (XRD), scanning electron microscope (SEM). In order to investigate magnetic properties of the sintered magnets on a pulsed high field magnetometer, the specimens of cylinders with $3 \mathrm{~mm}$ diameter and $3 \mathrm{~mm}$ height were cut from the magnets. To calculate the maximum energy product $(\mathrm{BH})_{\max }$ demagnetization factor was estimated based on a semiexperimental data sheet.

\section{Results and discussion}

Fig. 1 shows SEM images of additional compounds powder with milling time of $4 \mathrm{~h}$. We can see that with the P2 sample, the grains is coalesced so it is difficult to observe individual grains.

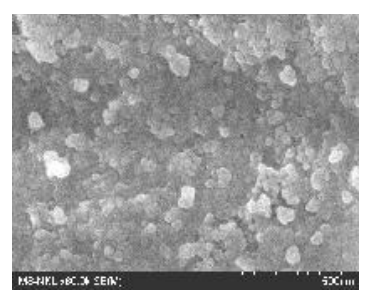

a)

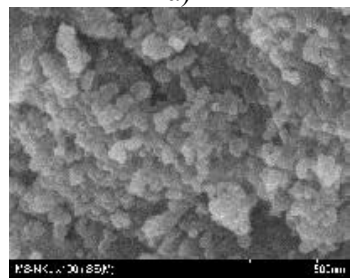

c)

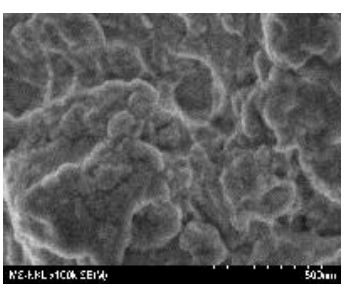

b)

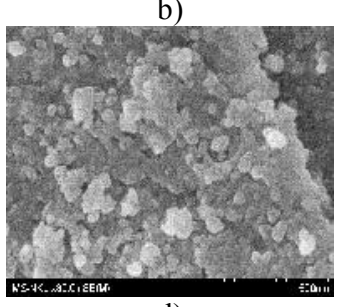

d)
Fig. 1. SEM images of the P1 (a), P2 (b), P3 (c) and P4 (d) powder with milling time of $4 \mathrm{~h}$.

As for the P1, P3 and P4 powders, the grain size is relatively uniform, in the range of $40-80 \mathrm{~nm}$. This is the desired size to mix with the master Nd-Fe-B alloy powder. X.G. Cui et al. suggested that nanopowders are probably distributed on the surface of $\mathrm{Nd}_{2} \mathrm{Fe}_{14} \mathrm{~B}$ grains more evenly than micro-scale powders [19]. With the increased activity due to the higher surface energy, nanopowders would be melted first and then dissolved in the liquid phase during sintering, leading to a homogenous distribution of intergranular phase.

The structure of addition powders was further investigated through the XRD patterns (Fig. 2). However, the use of X-ray diffraction patterns is not to determine the crystalline phases in the samples, but only to confirm nanostructure of the obtained powders with above milling time. The results show that with the $4 \mathrm{~h}$ milling time, compounds of P1 and P4 still have relatively high crystalline diffraction peaks, but the fraction of these peaks is negligible. Meanwhile, with the other additional compounds, expanding, low intensity and non-sharp of diffraction peaks characterize for crystalline phase in nanometer size. It is agreed with obtained results from the SEM images.

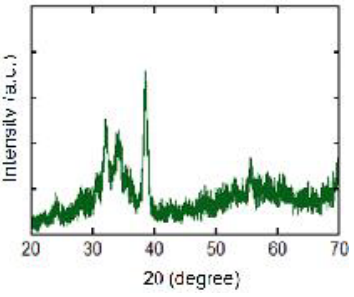

a)



c)

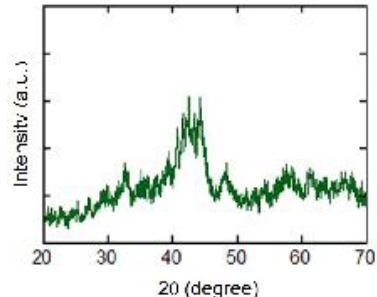

b)

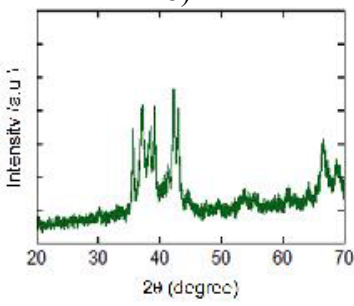

d)
Fig. 2. XRD patterns of $P 1$ (a), $P 2$ (b), $P 3$ (c) and P4 (d) powder with milling time of $4 \mathrm{~h}$.



Fig. 3. Hysteresis loops of the magnets added with $2 \mathrm{wt} \%$ of additional compounds after sintering at $1080^{\circ} \mathrm{C}$ for $1 \mathrm{~h}$.

In our previous study, the influence of $\mathrm{Dy}_{40} \mathrm{Nd}_{30} \mathrm{Al}_{30}$ nanopowders on magnetic properties of the sintered $\mathrm{Nd}$ Fe-B magnets was investigated. With $2 \mathrm{wt} \%$ of $\mathrm{Dy}_{40} \mathrm{Nd}_{30} \mathrm{Al}_{30}$ nanoparticles, the coercivity is significantly enhanced (above $20 \mathrm{kOe}$ ) [20]. For this study, $2 \mathrm{wt} \%$ of nanoparticles of the additional 
compounds were mixed with $\mathrm{Nd}-\mathrm{Fe}-\mathrm{B}$ master alloy powders having size of about 2-5 $\mu \mathrm{m}$. Hysteresis loops of un-added and added (without and with additional compounds) magnets after sintering at $1080^{\circ} \mathrm{C}$ for $1 \mathrm{~h}$ (as-sintered) are presented in Fig. 3. We can see that the hard magnetic properties of the added magnets are degraded with coercivity $\left(\mathrm{H}_{\mathrm{c}}<2 \mathrm{kOe}\right)$ lower than that of the un-added magnets $\left(\mathrm{H}_{\mathrm{c}}=5.5 \mathrm{kOe}\right)$ except the one added with $\mathrm{P} 1$ compound $\left(\mathrm{H}_{\mathrm{c}}=6.5 \mathrm{kOe}\right)$. We also realize that, the saturation magnetization of all the added magnets is decreased. This can be explained that, all of the addition compounds are non-ferromagnetic which reduces the volume fraction of ferromagnetic phase. On the other hand, the additional compounds can effect the ferromagnetic interaction of the materials, leading to the decrease of the saturation magnetization. However, the squareness of the hysteresis loops of the magnets is better. The reduction of coercivity probably is due to different optimal fabrication conditions for each addition compound, which contains different elements with different effects on sintering temperature and time. The $\mathrm{Dy}_{40} \mathrm{Nd}_{30} \mathrm{Al}_{30}$ additional compound of our previous study has the largest concentration of rare earth (70\%), which does not affect on sintering regime and creating high coercivity for the magnets.

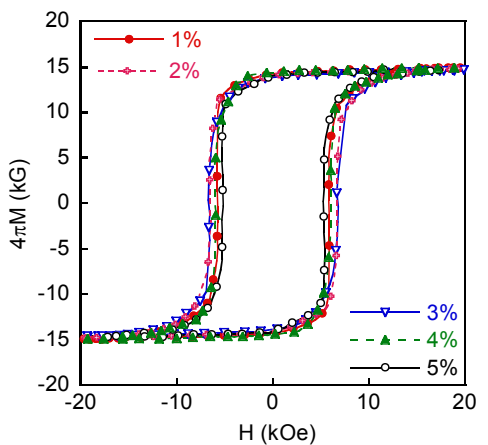

a)

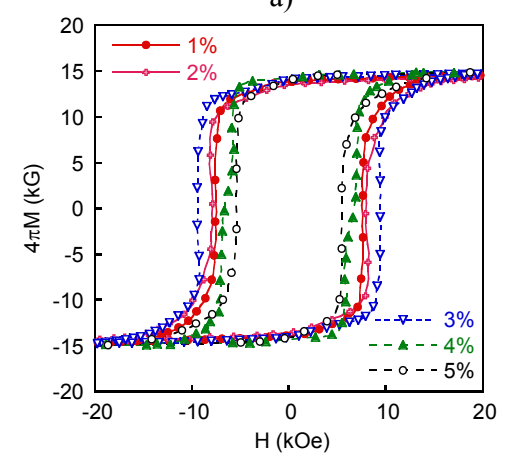

b)

Fig. 4. Hysteresis loops of the magnets added with various fractions of $\mathrm{Nd}_{40} \mathrm{Cu}_{30} \mathrm{Al}_{30}$ before (a) and after (b) heat treatment.

As well-known that, the Dy adding is an effective way to produce sintered Nd-Fe-B magnets with the high coercivity, which meets the application requirements for the motors and generators. However, the natural abundance of Dy is about 10 times less than that of $\mathrm{Nd}$ and its cost is much more expensive than that of $\mathrm{Nd}$ (about 4 times). Thus, investigations to enhance the coercivity without using Dy are important. In the fabricated additional compounds, the $\mathrm{Nd}_{40} \mathrm{Cu}_{30} \mathrm{Al}_{30}$ alloy in form of nanoparticles was chosen to investigate the influence of its weight fraction on magnetic properties of the magnets. Fig. 4 shows hysteresis loops of the magnets added with various fractions of $\mathrm{Nd}_{40} \mathrm{Cu}_{30} \mathrm{Al}_{30}$ before and after heat treatment. It can be realized that, the change of the coercivity on various fractions before heat treatment is not significantly. However, after heat treatment the coercivity was considerably enhanced and relatively changed with the different additional fractions. Nevertheless, the squareness of the hysteresis loops of the magnets is worse. In the second quadrant demagnetization curves of the heat-treated magnets, a small dip appears. These dips can be caused by physical or chemical modifications of the grain boundaries, which may reduce the local nucleation field. For examples, the formation of the soft magnetic $\alpha$-Fe phase would create nucleation centres for reversed magnetic domains resulting in the dips in the demagnetization curves of the added magnets.

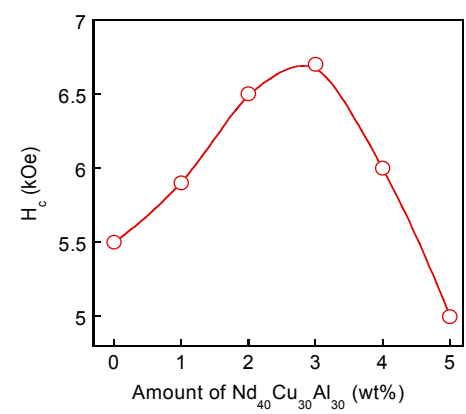

a)

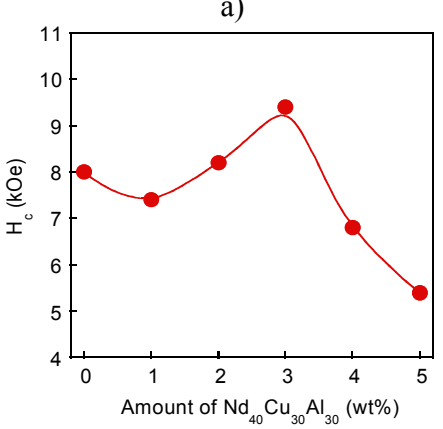

b)

Fig. 5. The dependences of coercivity $\mathrm{H}_{\mathrm{c}}$ of the added magnets on various fractions of $\mathrm{Nd}_{40} \mathrm{Cu}_{30} \mathrm{Al}_{30}$ before (a) and after (b) heat treatment.

The dependence of coercivity $\mathrm{H}_{\mathrm{c}}$ of the added magnets on various fractions of $\mathrm{Nd}_{40} \mathrm{Cu}_{30} \mathrm{Al}_{30}$ before and after heat treatment are shown in Fig. 5. We can see that the $\mathrm{H}_{\mathrm{c}}$ slightly increases as the $\mathrm{Nd}_{40} \mathrm{Cu}_{30} \mathrm{Al}_{30}$ amount increases from 1 to $2 \mathrm{wt} \%$ (from 5.8 to $6.5 \mathrm{kOe}$ for magnet before heat treatment, and from 7.5 to $8 \mathrm{kOe}$ for magnet after heat treatment). The highest coercivity for added magnets before and after heat treatment was obtained to be $6.7 \mathrm{kOe}$ and $9.5 \mathrm{kOe}$, respectively, with fraction of $3 \mathrm{wt} \%$. The $\mathrm{H}_{\mathrm{c}}$ decrease rather rapidly when the adding amount is over $3 \mathrm{wt} \%$. Therefore, the optimal additional amount of $\mathrm{Nd}_{40} \mathrm{Cu}_{30} \mathrm{Al}_{30}$ is $3 \mathrm{wt} \%$.

The reduction of the coercivity with large additional fractions (4 and $5 \mathrm{wt} \%$ ) probably is due to formation of disadvantage phases at grain boundaries for hard 
magnetic properties of the magnets. At the same time, heat treatment process might not create the desirous microstructure. Thus, the further enhancement of the coercivity of Dy-free sintered Nd-Fe-B magnets needs more carefully and systematically researches.

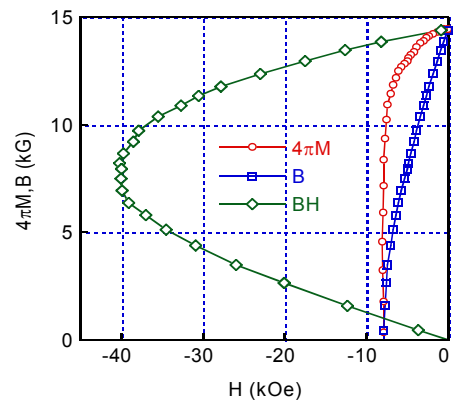

a)

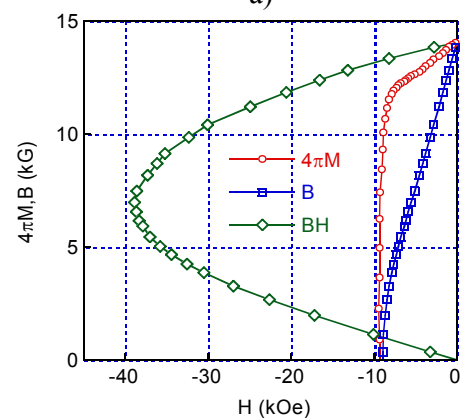

b)

Fig. 6. Magnetic characteristic curves of un-added (a) and 3\% $\mathrm{Nd}_{40} \mathrm{Cu}_{30} \mathrm{Al}_{30}$ added magnets (b) after heat treatment.

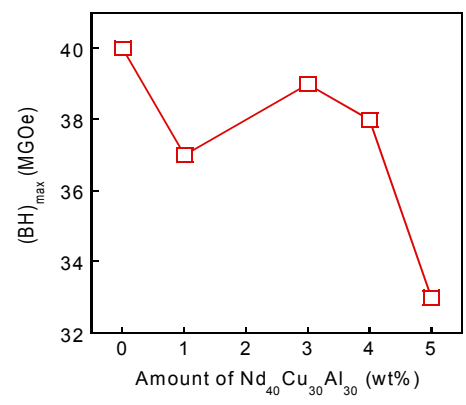

Fig. 7. The dependences of maximum energy product, $(\mathrm{BH})_{\max }$ of the added magnets on various fractions of $\mathrm{Nd}_{40} \mathrm{Cu}_{30} \mathrm{Al}_{30}$ after heat treatment.

Maximum energy product, $(\mathrm{BH})_{\max }$, of the un-added and 3 wt $\% \quad \mathrm{Nd}_{40} \mathrm{Cu}_{30} \mathrm{Al}_{30}$ added magnets after heat treatment was calculated to be $\sim 40$ MGOe and $\sim 38$ MGOe, respectively (Fig. 6). The lower $(\mathrm{BH})_{\max }$ of the added magnets with various fractions of $\mathrm{Nd}_{40} \mathrm{Cu}_{30} \mathrm{Al}_{30}$, as shown in Fig. 7, probably is due to a reduction of saturation magnetization by these non-ferromagnetic additional nanoparticles. These values of $(\mathrm{BH})_{\max }$ might be improved by an optimal heat treatment (further investigation of heat treatment is needed).

\section{Conclusion}

The influence of additional compounds on coercivity of the sintered $\mathrm{Nd}_{16.5} \mathrm{Fe}_{77} \mathrm{~B}_{6.5}$ magnets has been investigated. The highest coercivity, $\mathrm{H}_{\mathrm{c}}$, and the largest maximum energy product, $(\mathrm{BH})_{\max }$, have been obtained to be $9.5 \mathrm{kOe}$ and $38 \mathrm{MGOe}$, respectively, with $3 \%$ $\mathrm{Nd}_{40} \mathrm{Cu}_{30} \mathrm{Al}_{30}$ additional nanopowders and suitable technological conditions. The coercivity of the sintered $\mathrm{Nd}-\mathrm{Fe}-\mathrm{B}$ magnets can be increased $40 \%$ by addition of $\mathrm{Nd}_{40} \mathrm{Cu}_{30} \mathrm{Al}_{30}$ nanoparticles.

This work was supported by Vietnam Academy of Science and Technology under Grant number of VAST03.05/16-17. Some experiments were done in the Key Laboratory for Electronic Materials and Devices, Institute of Materials Science, Vietnam Academy of Science and Technology, Viet Nam.

\section{References}

1. Y. Matsuura, J. Magn. Magn. Mater. 303, 344 (2006)

2. J.M.D. Coey, Rare-earth iron permanent magnets (Clarendon Press, Oxford, 1996)

3. B.C. Chen, X.M. Liu, R.J. Chen, S. Guo, C.J. Yan, D. Lee, A.R. Yan, J. Appl. Phys. 111, 07A710-1 (2012)

4. H. Nakamura, K. Hirota, T. Ohashi, T. Minowa, J. Phys. D: Appl. Phys. 44, 064003-1 (2011)

5. Y. Liu, S. Guo, R. Chen, D. Lee, A. Yan, IEEE Trans. Magn. 47, 3270 (2011)

6. H. Sepehri-Amin, Y. Une, T. Ohkubo, K. Hono, M. Sagawa, Scri. Mater. 65, 396 (2011)

7. T. Kim, S. Lee, J. Kim, Y. Kim, H. Kim, M. Lee, T. Jang, J. Appl. Phys. 115, 17A770-1 (2014)

8. K. Kobayashi, K. Urushibata, Y. Une, M. Sagawa, J. Appl. Phys. 113, 163910-1 (2013)

9. N.Y. Yu, X.M. Pan, Y.P. Zhang, L.H. Ge, J. Magn. 18, 235 (2013)

10. X. Liu, T. Ma, X. Wang, M. Yan, J. Magn. Magn. Mater. 382, 26 (2015)

11. S.E. Park, T. Kim, S.R. Lee, S. Namkung, T.S. Jang, J. Appl. Phys. 111, 07A707-1 (2012)

12. M.W. Lee, D.R. Dhakal, T.H. Kim, S.R. Lee, H.J. Kim, T.S. Jang, Arch. Metal. Mater. 60, 1407 (2015)

13. L. Liang, T. Ma, P. Zhang, J. Jin, M. Yan, J. Magn. Magn. Mater. 355, 131 (2014)

14. Y. Zhang, T. Ma, X. Liu, P. Liu, J. Jin, J. Zou, M. Yan, J. Magn. Magn. Mater. 399, 159 (2016)

15. B. Zhou, X. Li, X. Cao, G. Yan, A. Yan, Chin. Phys. B 25, 117504-1 (2016)

16. M. Pan, P. Zhang, Q. Wu, H. Ge, Int. J. Electrochem. Sci. 11, 2659 (2016)

17. J.J. Ni, T.Y. Ma, Y.R. Wu, M. Yan, J. Magn. Magn. Mater. 322, 3710 (2010)

18. S. Lee, J. Kwon, H. Cha, K.M Kim, H. Kwon, J. Lee, D. Lee, Met. Mater. Int. 22, 340 (2016)

19. X.G. Cui, M. Yan, T.Y. Ma, L.Q. Yu, Phys. B 403, 4182 (2008)

20. N.H. Dan, P.T. Thanh, N.H. Yen, L.T. Hung, IEEE Trans. Magn. 50, 210204-1 (2014) 